\title{
Patients with double/triple copy number gains on C-MYC, BCL2, and/or BCL6 treated with standard chemotherapy have a similarly poor prognosis than those with high-grade B cell lymphoma with C-MYC and BCL2 and/or BCL6 rearrangements: a single-center experience on a consecutive cohort of large B cell lymphomas
}

\author{
Ella Willenbacher ${ }^{1} \cdot$ Wolfgang Willenbacher ${ }^{1,2} \cdot$ Roman Weger $^{2} \cdot$ Wolf Dominik $^{1} \cdot$ Claudia Manzl $^{3} \cdot$ Andrea Brunner $^{3}$
}

Received: 29 January 2020 / Accepted: 3 June 2020 / Published online: 1 July 2020

(C) The Author(s) 2020

\begin{abstract}
High-grade B cell lymphomas with rearrangements on C-MYC and BCL2 and/or BCL6 (HGBL with MYC and BCL2 and/or Bc16 rearrangement) are associated with worse clinical outcomes and thus were introduced as a separate new category in the recently updated WHO classification. From 2012 to 2016, we analyzed a consecutive cohort of large B cell lymphomas (LBCLs) for C-MYC, BCL2, and BCL6 rearrangements and correlated our results with clinical-pathological parameters. Ten of 78 (13\%) cases had a C-MYC and BCL2 and/or BCL6 rearrangement, so-called double or triple hit (DH), while double/triple copy number gains (CNGs) were found in eight (10\%) patients. Patients with a high-grade lymphoma with DH or CNG progressed significantly more often after first-line chemotherapy $(p=0.005)$. When treated with standard chemotherapy, patients with a DH or CNG had a significantly worse overall (OS) and recurrence free survival (RFS) compared with all other patients $(p=0.033$ and $p<0.001$, respectively). Thus, patients with a diffuse large $\mathrm{B}$ cell lymphoma, harboring a double/triple CNG, seem to have a similar poor prognosis than those with a DH. Though our data can only be regarded as preliminary, our results warrant further investigations to fully elucidate the role of CNGs as well as underlying molecular mechanisms resulting in aggressive behavior in LBCL.
\end{abstract}

Keywords HGBL $\cdot$ DLBCL $\cdot$ Double hit $\cdot$ C-MYC $\cdot$ BCL2 $\cdot$ BCL6

\section{Introduction}

Large B cell lymphomas (LBCLs) comprise a heterogeneous group of lymphomas. While some of them, such as Burkitt lymphoma, have a well-defined morphology and molecular pathology, others are less well defined and disease outcome is highly variable. Especially, the group of diffuse large B cell

Ella Willenbacher

ella.willenbacher@i-med.ac.at

1 Internal Medicine V - Haematology and Oncology, Medical University of Innsbruck, Innsbruck, Tyrol, Austria

2 ONCOTYROL - Center for personalized Cancer Medicine, Innsbruck, Austria

3 Institute of Pathology, Neuropathology and Molecular Pathology, Medical University of Innsbruck, Innsbruck, Austria lymphomas, not otherwise specified (DLBCL, NOS) consists of different morphological, immunohistochemical, and molecular subgroups and various subtypes significantly differing in clinical behavior and treatment outcome [1]. The WHO classification of hematopoietic tumors from 2008 introduced a provisional entity called large cell B cell lymphoma with features between a DLBCL, NOS and Burkitt lymphoma (BCLU) including large B cell lymphomas with Burkitt-like morphology, but distinct immunohistological features and the frequent presence of C-MYC rearrangements often together with a BCL2 and/or BCL6 rearrangement, so-called double/ triple hit (DH) $[2,3]$. These cases have been widely discussed in the literature and have been associated with a poor prognosis [4-7]. However, rearrangements of C-MYC together with BCL2 and/or BCL6 have also been reported in otherwise classical DLBCL, NOS $[8,9]$. In addition, ill-defined criteria for diagnosing BCLU have prevented a more consistent and comprehensible usage of the diagnosis $[10,11]$. Therefore, the 
current WHO classification includes all B cell lymphomas with rearrangements of C-MYC and BCL2 and/or BLC6 into the category of high-grade $\mathrm{B}$ cell lymphomas with rearrangements of C-MYC and BCL2 and/or BLC6 (HGBL with MYC and BCL2 and/or BCL6 rearrangement) irrespective of morphology, while lymphomas without rearrangement, which would otherwise fit into the former category of BCLU, are now summarized as HGBL, NOS [12].

Beside C-MYC rearrangements, expression of C-MYC protein $>40 \%$ together with BCL2 expression in $>50 \%$ of lymphoma cells has been reported to be associated with a poor outcome which is however better than in HGBL, C-MYC. Therefore, overexpression is only seen as a prognostic factor $[9,12]$. In addition, several studies point towards a role of copy number gains $(\mathrm{CNG})$ on C-MYC and/or BCL2 and/or BCL6 [13-15]. In fact, patients with CNG are reported to have a similarly poor prognosis than those with HGBL with MYC and BCL2 and/or BCL6. [13-15].

There is currently no agreement if an analysis for a CMYC, BLC2, and BCL6 rearrangement should be done in every DLBCL, NOS upon diagnosis or should be restricted to cases with GCB phenotype, a high-grade morphology, or C-MYC positivity [12].

From 2012 to 2016, we analyzed a consecutive cohort of DLBCL, NOS for the presence of C-MYC, BCL2, and BCL6 rearrangements and correlated our results with clinicalpathological parameters.

\section{Material and methods}

\section{Patients}

From 2012 to 2016, all LBCLs diagnosed at the Institute of Pathology, Neuropathology, and Molecular Pathology, Medical University of Innsbruck, were upon diagnosis routinely analyzed for the presence of rearrangements on CMYC, as well as BCL2 and BCL6 by means of fluorescence in situ hybridization (FISH), irrespective if they were de novo lymphomas or transformed from an underlying small cell lymphoma. Specimens included biopsies from lymph nodes, extra nodal sites, and bone. The study was conducted according to the ICH-GCP guidelines and the declaration of Helsinki. Ethical approval was obtained from the ethical committee of the Medical University of Innsbruck, and all patients gave an informed consent for study participation (EK-Nr.1213/2017).

\section{Morphology and immunohistochemistry}

Immunohistochemistry and EBER in situ hybridization were done upon diagnosis using an automated platform (Benchmark ULTRA, Ventana Medical Systems, Tucson, USA). The following antibodies were routinely applied:
CD20 (clone L26, prediluted, Ventana Medical Systems, Tucson, USA), CD79 (clone SP19, prediluted, Ventana Medical Systems, Tucson, USA), CD5 (clone SP19, prediluted, Ventana Medical Systems, Tucson, USA), Ki67 (clone Mib-1, dilution 1:100, DAKO, Leiden, the Netherlands), CD10 (clone SP67 prediluted, Ventana Medical Systems, Tucson, USA), BCL2 (clone 124, prediluted, Ventana Medical Systems, Tucson, USA), BCL6 (clone GI191E/A8, prediluted, Ventana Medical Systems, Tucson, USA), MUM1 (clone MRQ 43, prediluted, Ventana Medical Systems, Tucson, USA), C-MYC (clone Y69, prediluted, Ventana Medical Systems, Tucson, USA), and INFORM EBER (Epstein-Barr virus early RNA) Probe (Cat. Nr. 800-2842, Ventana Medical Systems, Tucson, USA).

All LBCLs were classified according to the WHO classification of tumors of the hematopoietic and lymphoid tissues (2008) and in addition were subdivided into germinal center (GCB) and non-germinal center (non-GCB) subtypes $[2,16]$. A cutoff of $40 \%$ C-MYC and 50\% BCL2 positive lymphoma cells was used to identify double expressors $[9,12]$.

\section{Fluorescence in situ hybridization}

FISH for C-MYC, BCL2, and BCL6 was performed using dual color break apart probes for each locus (Z-290-200 ZytoLight SPEC MYC Dual Color Break Apart Probe, Z2192-200 ZytoLight SPEC BCL2 Dual Color Break Apart Probe, and Z-2177-200 ZytoLight SPEC BCL6 Dual Color Break Apart probe; Zytovision, Bremerhaven, Germany). Tissue was mounted in a DAPI containing mounting media (Zytovision, Bremerhaven, Germany), and interphase nuclei were monitored using a fluorescence microscope (Axioplan 2, Zeiss, Oberkochen, Germany) equipped with a $63 \times$ oil objective.

For evaluation, at least 100 non-overlapping nuclei with sufficient bright signals in at least 3 areas had to be evaluated. CNGs were diagnosed when there were $\geq 3$ fusion signals/ cell. We did not distinguish between high ( $>5$ fusion signals) and low amplifications because current literature did not report any difference in survival between high and low copy numbers [13]. The cutoffs for considering a tumor sample positive for MYC, BCL2, and BCL6 by FISH were determined by assessing 10 normal lymph nodes (100 nuclei per sample) and choosing cutoffs of three standard deviations above the mean. The cutoffs were low for both split signals and CNGs $(\leq 3 \%)$, but cases involved in the study in general had abnormalities (split signals, CNGs) in $\geq 10 \%$ of nuclei. Therefore, we considered all cases with $\leq 10 \%$ (and $\geq 3 \%$ ) abnormalities with caution and increased the number of nuclei counted or repeated the FISH analysis, if necessary. Ultimately, only one case out of $78(1.2 \%)$, which was then regarded as negative, had to be repeated. 


\section{Clinical characteristics and treatment}

Clinical data, such as age, sex, Ann Arbor stage, International Prognostic Index (IPI), and lactate dehydrogenase (LDH) levels at diagnosis, as well as firstline treatment and response to treatment were retrospectively collected from patients' files at the University Clinics of Internal Medicine V, Hematology \& Oncology. According to Cheson et al., response criteria were defined as complete response confirmed (CRc), complete response unconfirmed $(\mathrm{CRu})$, partial response $(\mathrm{PR})$, stable disease (SD), and progressive disease (PD). Results of the FISH analysis did not influence the choice of treatment [17].

\section{Statistical analysis}

The Statistical Package of Social Sciences (SPSS 26.0 for Windows) was used. The $\chi^{2}$ test was used to test the relationship between HGL-DH, DLBCL-CNG, and DLBCL without DH-CNG and clinical as well as pathological parameters. Differences concerning overall survival and recurrence free survival between HGL-DH, DLBCL-CNG, and DLBCL without DH-CNG were analyzed by the Kaplan-Meier method and compared by the log rank test. A multivariate analysis was performed to identify independent prognostic markers for OS and RFS using a Cox multistep regression model. A $p$ value $<0.05$ was considered significant.

\section{Results}

\section{Patients}

Our study cohort finally included 78 patients (44 men and 34 women) with a mean age of 62.47 years, range from 25 to 93) with a diagnosis of DLBCL, NOS, or BCLU. Other specific types of aggressive lymphomas such as Burkitt lymphoma, primary mediastinal large $\mathrm{B}$ cell lymphoma, $\mathrm{EBV}^{+}$DLBCL, or plasmablastic lymphoma were excluded upon diagnosis. According to the WHO 2008, of the 78 patients, 76 (97.5\%) were classified as DLBCL, NOS including four patients with a known history of underlying small cell lymphoma (one chronic lymphocytic leukemia and three follicular lymphomas) and two $(2.5 \%)$ patients were diagnosed as BCLU. Three lymphomas were diagnosed as monomorphic B cell post-transplant lymphoproliferative disease (monomorphic B cell PTLD) fulfilling the criteria of DLBCL: one EBV positive and two EBV negative. One DLBCL was HIV associated and EBV positive. Thirty-three cases were initially diagnosed in a lymph node while 45 were diagnosed in an extra nodal site such as the liver and soft tissue and bone.
Fluorescence in situ hybridization and reclassification

FISH results were available for BCL2 in 76/78 (97\%), for BCL6 in 70/78 (90\%), and for C-MYC in 77/78 (99\%) patients. Lack of data was due to limited material. Six DLBCL, NOS, and one BCLU had a "double hit" (four with C-MYC/ BCL2 and two with C-MYC/BCL6) while two DLBCL, NOS and one BCLU presented with a "triple hit"; thus, these 10 (13\%) cases would now most likely have been classified into the category of HGBL with MYC and BCL2 and/or BCL6 rearrangement.

Rearrangements on either C-MYC or BCL2 or BCL6 were found in three (4\%), eight (10\%), and $10(13 \%)$ cases of DLBCL, NOS. CNGs on C-MYC and BCL2 and/or BCL6 were present in eight (10\%) cases. In three cases with double/ triple CNG an additional BCL2 rearrangement and in two an additional BCL6 rearrangement were detected. In addition, it should be noted that no rearrangement or double/triple $\mathrm{CNG}$ was found in all three PTLDs: the transformed CLL, a transformed FL, and the HIV+ DLBCL. One secondary DLBCL, NOS arising from a FL had a DH, while in one transformed lymphoma, FISH could not be evaluated and the case was therefore excluded from analysis. Patient's clinical and pathological characteristics are summarized in detail in Table 1. For statistical analysis, the $10(13 \%)$ cases with a DH were summarized as high-grade double hit lymphoma (HGL-DH), the $8(10 \%)$ cases with double/triple CNG as DLBCL-CNG (taken together as LBCL-DH-CNG), and the remaining 60 cases as DLBCL without DH-CNG.

\section{Pathological characteristics}

Of the 78 patients, 41 were classified as GCB and 36 as nonGCB subtype, while in one case, the immunohistochemical subtype could not be determined due to limited tissue. The majority of HGL-DH was of GCB subtype; however, one case was classified as non-GCB subtype. Expression of C-MYC was available in 59/78 (76\%) cases, including 5/10 (50\%) HGL-DH as well as 5/8 (62\%) DLBCL-CNG. BCL2 immunohistochemistry was done in 77/78 (99\%) cases. C-MYC expression $>40 \%$ and BCL2 expression in $>50 \%$ of lymphoma cells were detected altogether in 12/58 (21\%) cases. However, only six patients $(10 \%)$ were true "double expressors" while one case had a C-MYC rearrangement only and the other five (8\%) cases belonged to the HGL-DH group. All five DLBCL-CNGs, where C-MYC immunohistochemistry was available, showed a C-MYC expression $<40 \%$. Also, DLBCL-CNG compared to HGL-DH and DLBCL without DH-CNG had a significantly lower expression of CD10 ( $p$ chi-square $=0.02$ ), a higher expression of BCL2 and MUM1 ( $p^{\text {chi-square }}=0.09$ and $<0.001$, respectively) and thus significantly more often belonged to the non-GCB subgroup ( $p^{\text {chi- }}$ ${ }^{\text {square }}=0.05$; see Table 1 ). 
Table 1 Clinical and pathological characteristics of the 78 patients

\begin{tabular}{|c|c|c|c|c|c|}
\hline & & $\begin{array}{l}\text { HGL-DH } \\
(N=10)\end{array}$ & $\begin{array}{l}\text { DLBCL- } \\
\text { CNG } \\
(N=8)\end{array}$ & $\begin{array}{l}\text { DLBCL without } \\
\text { DH-CNG }(N=60)\end{array}$ & $p$ value \\
\hline \multirow[t]{2}{*}{ Age } & $<65$ & $6(60 \%)$ & $3(38 \%)$ & $30(50 \%)$ & 0.59 \\
\hline & $>65$ & $4(40 \%)$ & $5(62 \%)$ & $30(50 \%)$ & \\
\hline \multirow[t]{2}{*}{ Sex } & Male & $4(40 \%)$ & $6(75 \%)$ & $34(57 \%)$ & 0.39 \\
\hline & Female & $6(60 \%)$ & $2(15 \%)$ & $26(43 \%)$ & \\
\hline \multirow[t]{3}{*}{ Stage } & I-II & $2(20 \%)$ & $0(0 \%)$ & $17(28 \%)$ & 0.30 \\
\hline & III-IV & $6(60 \%)$ & $7(88 \%)$ & $37(62 \%)$ & \\
\hline & Unknown & $2(20 \%)$ & $1(12 \%)$ & $6(10 \%)$ & \\
\hline LDH & Elevated & $6(60 \%)$ & $6(75 \%)$ & $28(47 \%)$ & 0.15 \\
\hline \multirow[t]{5}{*}{ IPI Score } & Low & $1(10 \%)$ & $1(12.5 \%)$ & $13(21 \%)$ & 0.49 \\
\hline & Low-intermediate & $1(10 \%)$ & $4(50 \%)$ & $13(21 \%)$ & \\
\hline & High-intermediate & $3(30 \%)$ & $1(12.5 \%)$ & $15(25 \%)$ & \\
\hline & High & $3(30 \%)$ & $1(12.5 \%)$ & $14(23 \%)$ & \\
\hline & Unknown & $2(20 \%)$ & $1(12.5 \%)$ & $6(10 \%)$ & \\
\hline \multirow[t]{2}{*}{ Localization } & Nodal & $6(60 \%)$ & $3(38 \%)$ & $24(40 \%)$ & 0.63 \\
\hline & Extranodal & $4(40 \%)$ & $5(62 \%)$ & $36(60 \%)$ & \\
\hline \multirow[t]{5}{*}{ Immunohistochemistry } & BCL $2>50 \%+$ & $7(70 \%)$ & $8(100 \%)$ & $34(57 \%)$ & 0.09 \\
\hline & BCL6 + & $7(70 \%)$ & $5(62 \%)$ & $35(58 \%)$ & 0.77 \\
\hline & $\mathrm{CD} 10+$ & $9(90 \%)$ & $3(38 \%)$ & $26(43 \%)$ & 0.02 \\
\hline & MUM1 + & $2(20 \%)$ & $6(75 \%)$ & $35(58 \%)$ & 0.06 \\
\hline & $\begin{array}{l}\text { C-MYC }>40 \% \\
+^{*}\end{array}$ & $5(100 \%)$ & $0(0 \%)$ & $12(22 \%)$ & $<0.001$ \\
\hline \multirow[t]{3}{*}{ Double expressors } & Yes & $5(50 \%)$ & $0(0 \%)$ & $7(10 \%)$ & $<0.001$ \\
\hline & No & $0(0 \%)$ & $6(75 \%)$ & $41(68 \%)$ & \\
\hline & Unknown & $5(50 \%)$ & $2(25 \%)$ & $12(22 \%)$ & \\
\hline \multirow[t]{3}{*}{ Hans classifier } & GCB & $9(90 \%)$ & $3(38 \%)$ & $29(48 \%)$ & 0.05 \\
\hline & Non-GCB & $1(100 \%)$ & $5(62 \%)$ & $30(50 \%)$ & \\
\hline & Unknown & $0(0 \%)$ & $0(0 \%)$ & $1(1.5 \%)$ & \\
\hline \multirow[t]{4}{*}{ Ki67 } & Mean $(\%)$ & 85.50 & 83.13 & 78.6 & 0.41 \\
\hline & Median (\%) & 90 & 87.5 & 80 & \\
\hline & $<90$ & $4(40 \%)$ & $4(50 \%)$ & $37(61 \%)$ & 0.29 \\
\hline & $\geq 90$ & $6(60 \%)$ & $4(50 \%)$ & $22(36 \%)$ & \\
\hline \multirow[t]{4}{*}{ Rearrangement } & BCL2 + & $8(80 \%)$ & $3(38 \%)$ & $5(12 \%)$ & $<0.001$ \\
\hline & BCL6 + & $5(50 \%)$ & $2(25 \%)$ & $8(15 \%)$ & $<0.001$ \\
\hline & C-MYC + & $\begin{array}{l}10 \\
(100- \\
\%)\end{array}$ & $0(0 \%)$ & $3(6 \%)$ & $<0.001$ \\
\hline & $\begin{array}{c}\text { Double/triple } \\
\mathrm{CNG}+\end{array}$ & $0(0 \%)$ & $8(100 \%)$ & $0(0 \%)$ & $<0.001$ \\
\hline
\end{tabular}

$N$ number of cases, $L D H$ lactate dehydrogenase

*Only available in 59 cases including 5 HGL-DH

\section{Treatment and disease response}

Information on treatment was available in 70/78 (90\%) and on disease response in 59/78 (76\%) patients. While the vast majority of patients received standard treatment, four $(5 \%)$ patients had a palliative treatment and four $(5 \%)$ patients did not receive any therapy, mainly due to very old age ( $>90$ years) and co-morbidities. The standard treatment consisted of R-CHOP (42 patients) and CHOP-like therapy (R-COMP in 14 patients and $\mathrm{R}^{2}$-CHOP in two patients) as well as escalated regimens in 4 patients (GMALL, R-DA-EPOCH). Of eight (10\%) patients, no information on first-line treatment was available. While in DLBCL without DH-CNG, CR was achieved in nearly half (47\%) of the patients; 6/10 (60\%) patients with HGL-DH and 3/8 (38\%) patients with DLBCL-CNG had PD after initial treatment $\left(p^{\text {chi- }}\right.$ ${ }_{\text {square }}=0.005$; see Table 2).

\section{Overall survival}

Patients with DLBCL-CNG and HGL-DH had a significantly worse OS than those with DLBCL without DH-CNG (4/6 (66\%) DLBCL-CNG, median OS 12 months versus 6/9 (66\%) HGL-DH, median OS 27 months versus 16/52 (31\%) DLBCL without DH-CNG, median OS not reached; $p^{\log \text { rank }}=$ 0.008; see Fig. 1a). When comparing only patients with HGL-DH and all other DLBCL, NOS (including also DLBCL-CNG) data only showed a tendency for worse OS for HGL-DH $(p=0.09)$. Taken together, in all patients with 
LBCL with C-MYC, BCL2, and BCL6 alterations (LBCLDH-CNG), a worse OS was observed compared to DLBCL without $\mathrm{DH}-\mathrm{CNG}\left(p^{\log \text { rank }}=0.004\right)$.

When the analysis was restricted to patients, who received standard treatment, patients with LBCL-DH-CNG still had a worse OS than those with DLBCL without DH-CNG (6/11 (54.5\%) LBCL-DH-CNG, median OS 27 months versus 11/ 44 (25\%) DLBCL without DH-CNG, median OS not reached; $p^{\log \text { rank }}=0.033$ ).

Stratified for age, stage, LDH at diagnosis, IPI, risk stratification, extra nodal localization of disease Ki67 and cell of origin subtype (GCB versus non-GCB) age $>65$ years $\left(p^{\log }\right.$ rank $=0.015)$, stage III-IV $\left(p^{\log \text { rank }}=0.037\right)$, GCB subtype $(p$ $\log$ rank $=0.019)$, extra nodal localization $\left(p^{\log \text { rank }}<0.001\right)$, and Ki67 $>90 \%\left(p^{\text {log rank }}=0.04\right)$ were significantly associated with a worse OS for patients with LBCL-DH-CNG treated with standard chemotherapy.

Beside DH-CNG, the only other factors significantly influencing OS in patients treated with standard therapy was stage $\left(p^{\log }\right.$ rank $^{2} 0.046$ ), while IPI and risk stratification only showed a tendency for worse OS for high IPI (4-5) and high intermediate/ high risk lymphomas $\left(p^{\log \text { rank }}=0.149\right.$ and 0.073 , respectively).

Multivariate analysis including DH-CNG status, stage, IPI, and risk stratification showed that none is an independent prognostic factor for worse OS in patients treated with standard chemotherapy.

\section{Recurrence free survival}

Patients with HGL-DH had a significantly worse recurrence free survival than those with DLBCL, NOS (including
DLBCL-CNG) $\left(p^{\log \text { rank }}=0.013\right)$. DLBCL-CNGs were also associated with significantly shorter RFS similar to patients with HGL-DH (3/8 (38\%) DLBCL-CNG, median RFS 12 months versus 5/9 (55\%) HGL-DH, median RFS 13, months versus $11 / 53(21 \%)$ DLBCL without DH-CNG, median RFS not reached; $p^{\log \text { rank }}=0.001$; see Fig. 2a). Taken together, all patients with LBCL-DH-CNG had a worse RFS compared to DLBCL without DH-CNG $\left(p^{\log \text { rank }}<0.001\right)$.

This also holds true when analysis was restricted to patients receiving standard treatment (8/13 (61.5\%) LBCL-DH-CNG, median RFS 12 months versus 9/45 (20\%) DLBCL without DH-CNG, median RFS not reached; $p^{\log \text { rank }}<0.0001$; see Fig. 2b).

Stratified for age, stage, LDH at diagnosis, IPI, risk stratification, localization of disease, and Ki67 proliferation index, a significantly worse RFS was observed in LBCL-DH-CNG patients with age $>65$ years $\left(p^{\log \text { rank }}<0.0001\right)$, stage III-IV $\left(p^{\log \text { rank }}<0.0001\right)$, IPI $0-3\left(p^{\log \text { rank }}<0.001\right)$, pathologic $\mathrm{LDH}$ at diagnosis $\left(p^{\log \text { rank }}=0.001\right)$, and $\mathrm{Ki} 67>90 \%\left(p^{\log }\right.$ rank $=0.001$ ).

Neither age nor stage, IPI, risk stratification, LDH at diagnosis, localization of disease, and Ki67 proliferation index alone significantly influenced RFS.

\section{Discussion}

In our consecutive cohort of DLBCL, NOS, we identified 10 (12\%) HGL-DH and three (4\%) DLBCL, NOS with C-MYC rearrangement alone. Our data are in line with previous reports on the frequency of this type of lymphomas in a consecutive
Table 2 Treatment and response of the 78 patients in the study

\begin{tabular}{|c|c|c|c|c|c|}
\hline & & $\begin{array}{l}\text { HGL-DH } \\
(N=10)\end{array}$ & $\begin{array}{l}\text { DLBLC-CNG } \\
(N=8)\end{array}$ & $\begin{array}{l}\text { DLBCL without DH-CNG } \\
(N=60)\end{array}$ & $\begin{array}{l}p \\
\text { value }\end{array}$ \\
\hline \multirow{4}{*}{$\begin{array}{l}\text { First-line } \\
\text { treatment }\end{array}$} & Standard & $8(80 \%)$ & $5(62.5 \%)$ & $49(82 \%)$ & \multirow[t]{4}{*}{0.52} \\
\hline & Palliative & $0(0 \%)$ & $0(0 \%)$ & $4(66 \%)$ & \\
\hline & None & $1(10 \%)$ & $1(12.5 \%)$ & $2(3 \%)$ & \\
\hline & Unknown & $1(10 \%)$ & $2(25 \%)$ & $5(8 \%)$ & \\
\hline \multirow[t]{3}{*}{ Autologous Tx } & Yes & $2(20 \%)$ & $1(12.5 \%)$ & $6(10 \%)$ & \multirow[t]{3}{*}{0.28} \\
\hline & No & $6(60 \%)$ & $4(50 \%)$ & $47(78 \%)$ & \\
\hline & Unknown & $2(20 \%)$ & $3(37.5)$ & $7(12 \%)$ & \\
\hline \multirow[t]{4}{*}{ Initial response } & $\mathrm{CRc} / \mathrm{CRu}$ & $3(30 \%)$ & $2(25 \%)$ & $30(47 \%)$ & \multirow[t]{4}{*}{0.005} \\
\hline & $\mathrm{PR} / \mathrm{SD}$ & $0(0 \%)$ & $0(0 \%)$ & $9(15 \%)$ & \\
\hline & $\mathrm{PD}$ & $6(60 \%)$ & $3(38 \%)$ & $6(10 \%)$ & \\
\hline & Unknown & $1(10 \%)$ & $3(38 \%)$ & $15(25 \%)$ & \\
\hline \multirow[t]{3}{*}{ Recurrence } & Yes & $5(50 \%)$ & $3(38 \%)$ & $11(18 \%)$ & \multirow[t]{3}{*}{0.18} \\
\hline & No & $4(40 \%)$ & $5(62 \%)$ & $42(70 \%)$ & \\
\hline & Unknown & $1(10 \%)$ & $0(0 \%)$ & $7(12 \%)$ & \\
\hline \multirow[t]{3}{*}{ Survival } & Alive & $6(60 \%)$ & $4(50 \%)$ & $17(28 \%)$ & \multirow[t]{3}{*}{0.14} \\
\hline & Dead & $3(30 \%)$ & $2(25 \%)$ & $36(60 \%)$ & \\
\hline & Unknown & $1(10 \%)$ & $2(25 \%)$ & $7(12 \%)$ & \\
\hline
\end{tabular}

$N$ number of cases, Tx transplantation 


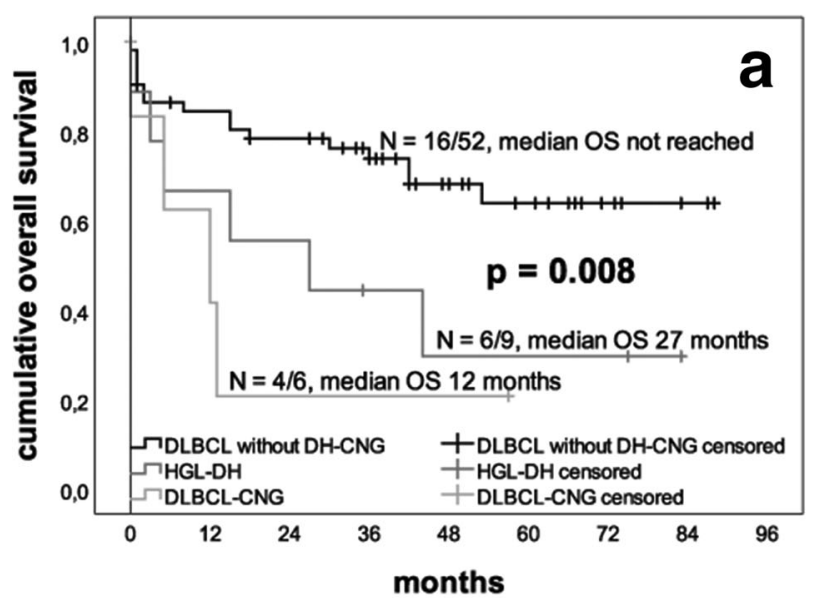

Fig. 1 Patients with HGL-DH and DLBCL-CNG have a significantly worse OS than those with DLBCL without DH-CNG (a); treated with standard chemotherapy, patients with LBCL-DH-CNG have a

cohort, which range from 3 to $21 \%$ depending upon the composition of patient population [5]. Double/triple CNGs were found in $10 \%$ of patients, where recent reports suggest a frequency of 3.8 to $6 \%$ of DLBCL, NOS $[13,15]$. The slightly higher number in our group may be due to the analysis of CMYC, BCL2, as well as BCL6 in virtually all cases, which is seldom done in routine diagnostics.

Our data on HGL-DH once more confirm the need for a different therapeutic approach in patients with LBCL harboring a C-MYC and BCL2 and/or BCL6 rearrangement, though none of the suggested escalated regimens, such as DA-EPOCH-R (dose-adjusted etoposide, prednisolone, vincristine, cyclophosphamide, doxorubicin, and rituximab) or R-CHOP-ibrutinib, proved to be superior in a randomized phase III setting so far $[6,18-23]$. As previously reported by other authors, in our study, cases with double/triple CNG had a similarly poor prognosis than HGL-DH [13-15]. Therefore, although the group of

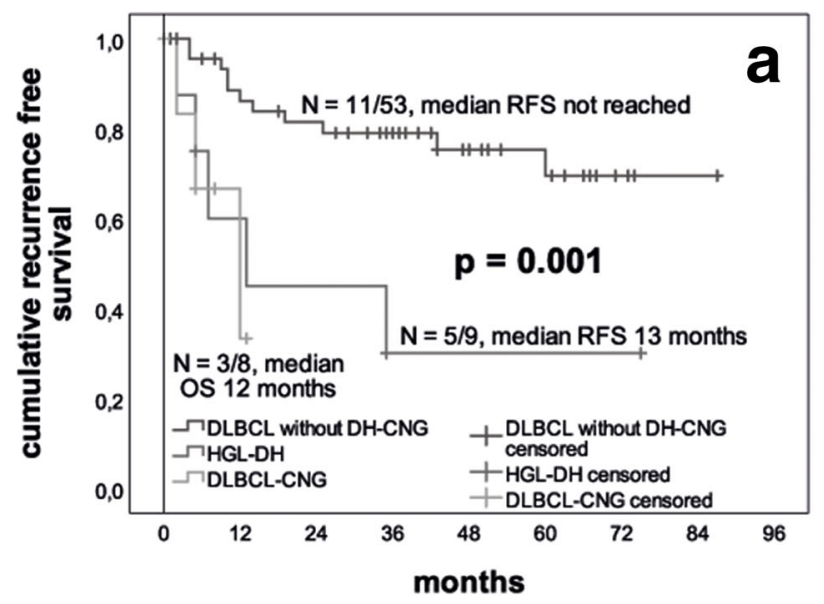

Fig. 2 Patients with HGL-DH and DLBCL-CNG have a significantly worse RFS than those with DLBCL without DH-CNG (a); treated with standard chemotherapy, patients with LBCL-DH-CNG have a

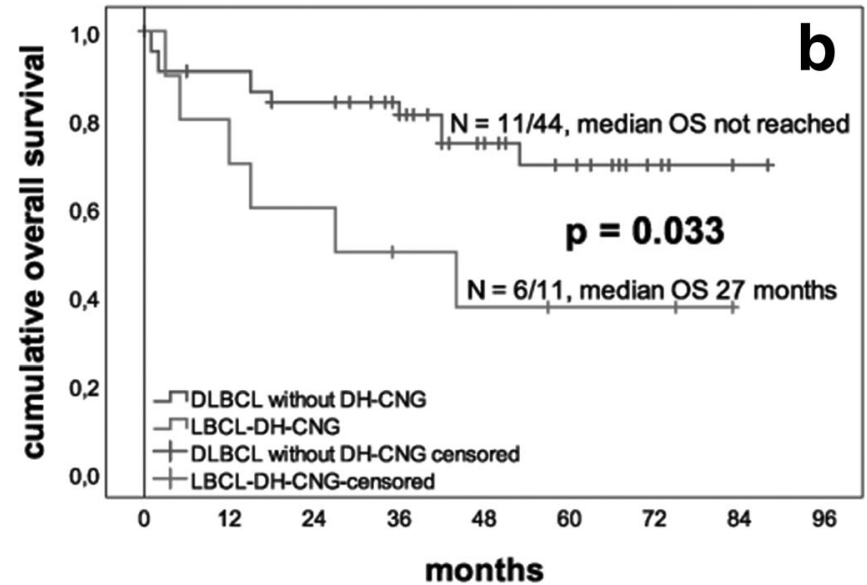

significantly worse OS than all other patients with DLBCL without DH-CNG (b) ( $N=$ number of events/number of cases $)$

HGL-DH includes lymphomas with a defined aberration, this group does not suit all those LBCL with a poor prognosis. Thus, the LBCLs with MYC alterations are not a homogeneous group. In fact, while HGL-DH cases usually show overexpression of C-MYC and GCB subtypes, cases with double/triple CNG lack C-MYC expression $>40 \%$ and more often belong to the $\mathrm{ABC}$-group, implicating that the mechanisms by which $\mathrm{C}$ MYC and BCL2 and/or BCL6 alterations finally influence prognosis may be different ones $[13,14]$. This is also supported by recent genetic data on DLBCL, NOS which show, depending on the method of analysis, up to five genetic subtypes of DLBCL, NOS, of which C-MYC rearranged or double/triple hit cases were usually part of but not exclusively formed the group of molecular high-grade lymphomas [24-27]. Therefore, further investigations are needed to fully decrypt the molecular basis for a more aggressive behavior in order to delimit this group of patients from all others.

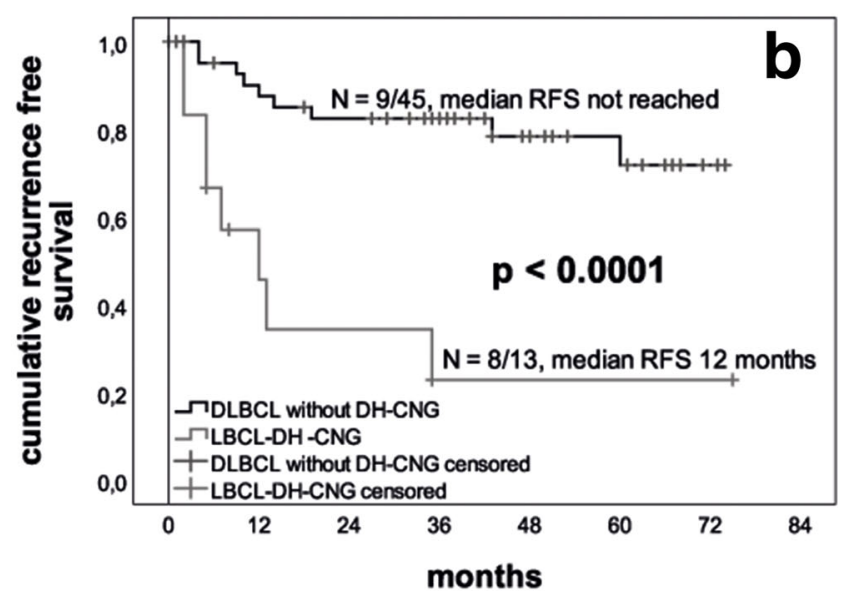

significantly worse RFS than all patients with DLBC without DH-CNG (b) $(N=$ number of events/number of cases $)$ 
Our study has some limitations. First of all, it is based upon a rather small and heterogeneous group of patients including also cases of known secondary DLBCL, NOS, though the majority of these clinically usual more aggressive lymphomas belonged to the group of DLBCL without CNG. Second, it represents the experience of only a single center; thus, to further support our results, a larger prospective and multicenter trial would be necessary. Third, due to the small numbers of DH-CNG cases, a further subdivision (i.e., low versus high amplification; amplification with/or without additional rearrangement on either CMYC or BLC2 or BCL6) could not be performed. Also, since the data were collected retrospectively, information upon polyploidy was not available for routine FISH and does not include centromere probes, but break apart probes for each specific locus.

According to the actual WHO, reporting double/triple CNG is not a mandatory component for the diagnosis of a DLBCL, NOS, but given the recent reports on clinical outcome, we suggest that double/triple CNG should be reported similar to overexpression of C-MYC and BCL2 [13-15]. This would require FISH at least for C-MYC rearrangement in any newly diagnosed DLBCL, NOS.

To summarize, though one cannot draw any definite conclusions from our data by now, we believe our results warrant further investigations in larger sample sets and preferably a prospective fashion to fully elucidate the role of CNGs as well as the underlying molecular mechanisms resulting in aggressive behavior in LBCL.

Acknowledgments The authors are grateful to Julia Heppke, Iris Oberauer, and Bianca Wasserbauer for their technical assistance.

Funding information Open access funding provided by University of Innsbruck and Medical University of Innsbruck. The Companies Roche and Celgene financially supported this work.

\section{Compliance with ethical standards}

The study was conducted according to the ICH-GCP guidelines and the declaration of Helsinki. Ethical approval was obtained from the ethical committee of the Medical University of Innsbruck, and all patients gave an informed consent for study participation (EK-Nr.1213/2017).

Conflict of interest The authors declare that they have no competing interests.

Open Access This article is licensed under a Creative Commons Attribution 4.0 International License, which permits use, sharing, adaptation, distribution and reproduction in any medium or format, as long as you give appropriate credit to the original author(s) and the source, provide a link to the Creative Commons licence, and indicate if changes were made. The images or other third party material in this article are included in the article's Creative Commons licence, unless indicated otherwise in a credit line to the material. If material is not included in the article's Creative Commons licence and your intended use is not permitted by statutory regulation or exceeds the permitted use, you will need to obtain permission directly from the copyright holder. To view a copy of this licence, visit http://creativecommons.org/licenses/by/4.0/.

\section{References}

1. O'Malley DP, Auerbach A, Weiss LM (2015) Practical applications in immunohistochemistry: evaluation of diffuse large B-cell lymphoma and related large B-cell lymphomas. Arch Pathol Lab Med 139(9):1094-1107

2. Swerdlow SH, Campo E, Harris NL, Jaffe ES, Pileri SA, Stein H, Thiele J eds (2008) WHO classification of tumours of hematopoietic and lymphoid tissues. Lyon: IARC Press; 194-95. World Health Organization Classification of Tumours; Vol 2

3. Campo E, Swerdlow SH, Harris NL, Pileri SA, Stein H, Jaffe ES (2011) The 2008 WHO classification of lymphoid neoplasms and beyond: evolving concepts and practical applications. Blood 117(19):5019-5032

4. Abramson JS, Barnes JA, Feng Y, Takvorian T, Neuberg D, Hochberg EP, Sohani AR (2012) Double hit lymphomas: evaluation of prognostic factors and impact of therapy. Blood 120:1619

5. Pedersen MØ, Gang AO, Poulsen TS, Knudsen H, Lauritzen AF, Nielsen SL, Gang UO, Nørgaard P (2012) Double-hit BCL2/MYC translocations in a consecutive cohort of patients with large B-cell lymphoma - a single centre's experience. Eur J Haematol 89(1):63-71

6. Oki Y, Noorani M, Lin P, Davis RE, Neelapu SS, Ma L, Ahmed M, Rodriguez MA, Hagemeister FB, Fowler N, Wang M, Fanale MA, Nastoupil L, Samaniego F, Lee HJ, Dabaja BS, Pinnix CC, Medeiros LJ, Nieto Y, Khouri I, Kwak LW, Turturro F, Romaguera JE, Fayad LE, Westin JR (2014) Double hit lymphoma: the MD Anderson Cancer Center clinical experience. Br J Haematol 166(6):891-901

7. Landsburg DJ (2017) Advancing the management of double hit lymphoma. Oncotarget 8(45):78245-78246

8. Johnson NA, Slack GW, Savage KJ, Connors JM, Ben-Neriah S, Rogic S, Scott DW, Tan KL, Steidl C, Sehn LH, Chan WC, Iqbal J, Meyer PN, Lenz G, Wright G, Rimsza LM, Valentino C, Brunhoeber P, Grogan TM, Braziel RM, Cook JR, Tubbs RR, Weisenburger DD, Campo E, Rosenwald A, Ott G, Delabie J, Holcroft C, Jaffe ES, Staudt LM, Gascoyne RD (2012) Concurrent expression of MYC and BCL2 in diffuse large B-cell lymphoma treated with rituximab plus cyclophosphamide, doxorubicin, vincristine, and prednisone. J Clin Oncol 30(28):3452-3459

9. Cheah CY, Oki Y, Westin JR, Turturro F (2015) A clinician's guide to double hit lymphomas. Br J Haematol 168(6):784-795

10. Swerdlow SH (2014) Diagnosis of 'double hit' diffuse large B-cell lymphoma and B-cell lymphoma, unclassifiable, with features intermediate between DLBCL and Burkitt lymphoma: when and how, FISH versus IHC. Hematology Am Soc Hematol Educ Program 2014(1):90-99

11. Momose S, Weißbach S, Pischimarov J, Nedeva T, Bach E, Rudelius M, Geissinger E, Staiger AM, Ott G, Rosenwald A (2015) The diagnostic gray zone between Burkitt lymphoma and diffuse large B-cell lymphoma is also a gray zone of the mutational spectrum. Leukemia 29(8):1789-1791

12. Swerdlow SH, Campo E, Pileri SA, Harris NL, Stein H, Siebert R, Advani R, Ghielmini M, Salles GA, Zelenetz AD, Jaffe ES (2016) The 2016 revision of the World Health Organization classification of lymphoid neoplasms. Blood 127(20):2375-2390

13. Quesada AE, Medeiros LJ, Desai PA, Lin P, Westin JR, Hawsawi HM, Wei P, Tang G, Seegmiller AC, Reddy NM, Yin CC, Wang W, Xu J, Miranda RN, Zuo Z, Li S (2017) Increased MYC copy number is an independent prognostic factor in patients with diffuse large B-cell lymphoma. Mod Pathol 30(12):1688-1697

14. Li S, Seegmiller AC, Lin P, Wang XJ, Miranda RN, Bhagavathi S, Medeiros LJ (2015) B-cell lymphomas with concurrent MYC and BCL2 abnormalities other than translocations behave similarly to MYC/BCL2 double-hit lymphomas. Mod Pathol 28:208-217

15. Lu TX, Fan L, Wang L, Wu JZ, Miao KR, Liang JH, Gong QX, Wang Z, Young KH, Xu W, Zhang ZH, Li JY (2015) MYC or 
BCL2 copy number aberration is a strong predictor of outcome in patients with diffuse large B-cell lymphoma. Oncotarget 6:1837418388

16. Hans CP, Weisenburger DD, Greiner TC, Gascoyne RD, Delabie J, Ott G, Müller-Hermelink HK, Campo E, Braziel RM, Jaffe ES, Pan Z, Farinha P, Smith LM, Falini B, Banham AH, Rosenwald A, Staudt LM, Connors JM, Armitage JO, Chan WC (2004) Confirmation of the molecular classification of diffuse large Bcell lymphoma by immunohistochemistry using a tissue microarray. Blood 103(1):275-282

17. Cheson B, Fisher RI, Barrington SF, Cavalli F, Schwartz LH, Zucca E, Lister TA (2014) Alliance, Australasian Leukaemia and Lymphoma Group; Eastern Cooperative Oncology Group; European Mantle Cell Lymphoma Consortium; Italian Lymphoma Foundation; European Organisation for Research; Treatment of Cancer/Dutch Hemato-Oncology Group; Grupo Español de Médula Ósea; German High-Grade Lymphoma Study Group; German Hodgkin's Study Group; Japanese Lymphoma Study Group; Lymphoma Study Association; NCIC Clinical Trials Group; Nordic Lymphoma Study Group; Southwest Oncology Group; United Kingdom National Cancer Research Institute. Recommendations for initial evaluation, staging, and response assessment of Hodgkin and non-Hodgkin lymphoma: the Lugano classification. J Clin Oncol 32(27):3059-3068

18. Petrich AM, Gandhi M, Jovanovic B, Castillo JJ, Rajguru S, Yang DT, Whyman JD SKA, Lansigan F, Hernandez-Ilizaliturri FJ, Lee LX, Barta SK, Melinamani S, Karmali R, Adeimy C, Smith S, Dalal N, Nabhan C, Peace D, Vose J, Evens AM, Shah N, Fenske T, Zelenetz AD, Landsburg DJ, Howlett C, Mato A, Jaglal M, Chavez JC, Tsai JP, Reddy N, Li S, Handler C, Flowers CR, Cohen JB, Blum KA, Song K, Sun H, Press O, Cassaday R, Jaso J, Medeiros LJ, Sohani AR, Abramson JS (2014) Impact of induction regimen and stem cell transplantation on outcomes in double-hit lymphoma: a multicenter retrospective analysis. Blood 124(15):2354-2361

19. Howlett, Snedecor SJ, Landsburg DJ, Svoboda J, Chong EA, Schuster SJ, Nasta SD, Feldman T, Rago A, Walsh KM, Weber S, Goy A, Mato A (2015) Front-line, dose-escalated immunochemotherapy is associated with a significant progression-free survival advantage in patients with double-hit lymphomas: a systematic review and metaanalysis. Br J Haematol 170(4):504-514

20. Phillips EH, Burton C, Kirkwood AA, Barrans S, Lawrie A, Rule S, Patmore R, Pettengell R, Ardeshna K, Montoto S, Paneesha S, CliftonHadley L, Linch D, Andrew McMillan A (2018) Favourable outcomes with R-CODOX-M/R-IVAC across all subgroups of aggressive high grade B-cell lymphoma: pathology and updated survival results from a UK phase 2 UK NCRI/Bloodwise trial. European Haemaotology Association Annual Meeting, Abst. 1548

21. Dunleavy K, Fanale MA, Abramson JS, Noy A, Caimi PF, Pittaluga S, Parekh S, Lacasce A, Hayslip JW, Jagadeesh D, Nagpal S, Lechowicz MJ, Gaur R, Lucas A, Roschewski MC, Steinberg SM, Jaffe ES, Kahl B, Friedberg JW, Little RF, Bartlett NL, Wilson WH (2018) Dose-adjusted EPOCH-R (etoposide, prednisone, vincristine, cyclophosphamide, doxorubicin, and rituximab) in untreated aggressive diffuse large B-cell lymphoma with
MYC rearrangement: a prospective, multicentre, single-arm phase 2 study. Lancet Haematol 5(12):e609-e617

22. Johnson P, Balasubramanian S, Hodkinson B, Schaffer M, Parisi L, Shreeve SM, Sun S, Vermeulen J, Sehn LH, Staudt L, Younes A, Wilson W (2019) Clinical impact of ibrutinib with R-CHOP in untreated non-GCB DLBCL co-expressing BCL2 and MYC genes in the phase 3 Phoenix trial. ASH Annual Meeting 2019, Session 626:354

23. Bartlett NL, Wilson WH, Jung SH, Hsi ED, Maurer MJ, Pederson LD, Polley MC, Pitcher BN, Cheson BD, Kahl BS, Friedberg JW, Staudt LM, Wagner-Johnston ND, Blum KA, Abramson JS, Reddy NM, Winter JN, Chang JE, Gopal AK, Chadburn A, Mathew S, Fisher RI, Richards KL, Schöder H, Zelenetz AD, Leonard JP (2019) Dose-adjusted EPOCH-R compared with R-CHOP as frontline therapy for diffuse large B-cell lymphoma: clinical outcomes of the Phase III Intergroup Trial Alliance/CALGB 50303. J Clin Oncol 37(21):1790-1799

24. Chapuy B, Stewart C, Dunford AJ, Kim J, Kamburov A, Redd RA, Lawrence MS, Roemer MGM, Li AJ, Ziepert M, Staiger AM, Wala JA, Ducar MD, Leshchiner I, Rheinbay E, Taylor-Weiner A, Coughlin CA, Hess JM, Pedamallu CS, Livitz D, Rosebrock D, Rosenberg M, Tracy AA, Horn H, van Hummelen P, Feldman AL, Link BK, Novak AJ, Cerhan JR, Habermann TM, Siebert R, Rosenwald A, Thorner AR, Meyerson ML, Golub TR, Beroukhim R, Wulf GG, Ott G, Rodig SJ, Monti S, Neuberg DS, Loeffler M, Pfreundschuh M, Trümper L, Getz G, Shipp MA (2018) Molecular subtypes of diffuse large B cell lymphoma are associated with distinct pathogenic mechanisms and outcomes. Nat Med 24(5):679-690

25. Schmitz R, Wright GW, Huang DW, Johnson CA, Phelan JD, Wang JQ, Roulland S, Kasbekar M, Young RM, Shaffer AL, Hodson DJ, Xiao W, Yu X, Yang Y, Zhao H, Xu W, Liu X, Zhou B, Du W, Chan WC, Jaffe ES, Gascoyne RD, Connors JM, Campo E, Lopez-Guillermo A, Rosenwald A, Ott G, Delabie J, Rimsza LM, Tay Kuang Wei K, Zelenetz AD, Leonard JP, Bartlett NL, Tran B, Shetty J, Zhao Y, Soppet DR, Pittaluga S, Wilson WH, Staudt LM (2018) Genetics and pathogenesis of diffuse large B-cell lymphoma. N Engl J Med 378:1396-1407

26. Sha C, Barrans S, Cucco F, Bentley MA, Care MA, Cummin T, Kennedy H, Thompson JS, Uddin R, Worrillow L, Chalkley R, van Hoppe M, Ahmed S, Maishman T, Caddy J, Schuh A, Mamot C, Burton C, Tooze R, Davies A, Du MQ, Johnson PWM, Westhead DR (2019) Molecular high-grade B-cell lymphoma: defining a poor-risk group that requires different approaches to therapy. J Clin Oncol 37(3):202-212

27. Ennishi D, Jiang A, Boyle M, Collinge B, Grande BM, Ben-Neriah S, Rushton C, Tang J, Thomas N, Slack GW, Farinha P, Takata K, Miyata-Takata T, Craig J, Mottok A, Meissner B, Saberi S, Bashashati A, Villa D, Savage KJ, Sehn LH, Kridel R, Mungall AJ, Marra MA, Shah SP, Steidl C, Connors JM, Gascoyne RD, Morin RD, Scott DW (2019) Double-hit gene expression signature defines a distinct subgroup of germinal center B-cell-like diffuse large B-cell lymphoma. J Clin Oncol 37(3):190-201

Publisher's note Springer Nature remains neutral with regard to jurisdictional claims in published maps and institutional affiliations. 